\title{
Simulação técnico-econômica da inclusão de ractopamina em dietas de suínos em terminação
}

\author{
R.C. Brumatti, C. Kiefer \\ Departamento de Zootecnia - UFMS \\ Caixa Postal 549 \\ 79070-900 - Campo Grande, MS
}

[Technical-economic simulation of ractopamine inclusion in diets for finishing pigs]

\begin{abstract}
RESUMO
Foi realizada simulação técnico-econômica a partir de resultados de publicações para avaliar a inclusão de ractopamina em dietas de suínos em terminação. Foram utilizados 18 artigos, que avaliaram níveis de 0,5 , 10 e/ou 20ppm de ractopamina na dieta, totalizando 2.991 animais. A partir dos resultados técnicos das publicações avaliadas, foram geradas equações que foram utilizadas na simulação do desempenho técnico-econômico. Verificou-se que os custos independem do sistema de receitas do produtor e oscilam de 3 a $6 \mathrm{ppm}$ de ractopamina adicionada à dieta. O lucro máximo foi obtido com os níveis de 10 e $12 \mathrm{ppm}$ de ractopamina, respectivamente, para os sistemas de receita por peso vivo e por bonificação. Os resultados evidenciam melhor desempenho econômico da utilização de ractopamina, na dieta dos suínos em terminação, pelo sistema de receita por bonificação. As análises de sensibilidade para a variação na receita dos produtores apresentam valores ótimos de 9 a $12 \mathrm{ppm}$ de ractopamina, com oscilação de até $\mathrm{R} \$$ 49,00/cabeça entre os cenários testados.
\end{abstract}

Palavras-chave: suíno, aditivo, avaliação econômica, carcaça, carne magra

\begin{abstract}
A technical-economic simulation was performed based on results from publications for assessing the inclusion of ractopamine in the diet of finishing pigs. Eighteen articles were used, which assessed levels of $0,5,10$, and/or 20ppm of ractopamine in the diet, totalizing 2,991 animals. Based on the results obtained in these technical publications, equations were used for the simulation of the technical-economic performance. From this study, it was established that the costs are independent of the system of revenue of the producer and range from 3 to 6ppm of ractopamine added in the diet. The maximum profit was obtained with the levels of 10 and 12ppm of ractopamine, respectively, for the systems of revenue per body weight and per bonus. The results show a better economic performance with the use of ractopamine in the diet of finishing pigs, by the system of revenue per bonus. Analyses of sensitivity of changes in the revenue of producers presented optimal values of 9 to $12 \mathrm{ppm}$ of ractopamine, with a range of up to $R \$$ 49.00 per capita between the tested scenarios.
\end{abstract}

Keywords: pig, additive, economic evaluation, carcass, lean meat, nutrition

\section{INTRODUÇÃO}

Desde 1970, quando o setor suinícola começou a mudar a imagem de seu produto conhecido como "porco tipo banha" e resolveu apostar no desenvolvimento do setor, a suinocultura nacional deu um grande salto produtivo, tornando-se um dos principais agentes mundiais no segmento por apresentar vantagens competitivas como: disponibilidade de terra, bons recursos humanos, baixo custo de produção, boas opções de grãos, forte parque industrial, menor incidência de enfermidades, clima favorável e boa tecnologia (Roppa, 2006). Além das

Recebido em 25 de junho de 2009

Aceito em 2 de fevereiro de 2010

E-mail: brumatti@nin.ufms.br 


\section{Brumatti e Kiefer}

mudanças no setor, os consumidores tornaram-se mais exigentes com relação à qualidade do produto cárneo que adquirem e consomem. Para atender a essas exigências, diversas pesquisas têm sido realizadas com o intuito de encontrar alternativas que permitam a redução na deposição de gordura e aumento da porcentagem de carne magra na carcaça dos suínos.

Dentre as alternativas está a ractopamina, aditivo beta-adrenérgico que vem sendo utilizado como repartidor de energia em dietas de suínos na fase de terminação, com o propósito de melhorar as características de carcaça. Tem-se constatado que os benefícios da sua utilização são o aumento da deposição de proteína (Apple et al., 2004) e a redução da deposição de gordura na carcaça (Perez et al., 2006), sem alterar, no entanto, a qualidade da carne suína (Herr et al., 2000).

Tem-se verificado que o aumento da deposição de proteína corporal proporcionado pela utilização da ractopamina é maior na carcaça em relação àquele verificado nas vísceras, o que promove melhora do rendimento de carcaça dos suínos (Schinckel et al., 2002). Além disso, dietas contendo $10 \mathrm{ppm}$ de ractopamina têm proporcionado redução do consumo de alimento (Brumm et al., 2004), aumento do ganho de peso (Armstrong et al., 2004) e aumento da eficiência de utilização dos alimentos pelos suínos (Mimbs et al., 2005). Em situações práticas, níveis entre 5 a $10 \mathrm{ppm}$ têm resultado em ganho de peso satisfatório, porém níveis maiores, em torno de $20 \mathrm{ppm}$, têm proporcionado máxima eficiência alimentar e melhores características quantitativas das carcaças dos suínos (See et al., 2004). Contudo, a ractopamina ainda é um produto que onera o custo de alimentação e, portanto, o custo total de produção dos suínos, mesmo sendo incluída em pequenas concentrações nas dietas.

Considerando que o custo de alimentação representa a principal parcela do custo de produção na suinocultura, aliada à carência de informações do impacto econômico da utilização de ractopamina na lucratividade do sistema de produção, propôs-se realizar este trabalho com o objetivo de estabelecer os níveis ótimos de inclusão de ractopamina nas dietas de suínos em terminação, com base na viabilidade econômica determinada a partir de resultados técnicos de desempenho e de características quantitativas das carcaças obtidos em estudos previamente publicados.

\section{MATERIAL E MÉTODOS}

Para realizar o estudo, foram selecionados e coletados dados de artigos científicos nacionais e internacionais, publicados entre 1990 e 2007. Artigos que relatam a associação entre desempenho e características de carcaça de suínos com a suplementação de ractopamina nas dietas foram considerados elegíveis. Foram identificadas 52 publicações, sendo excluídas 34 após a revisão. Na seleção dos artigos, foi feita restrição pela fase de criação e duração da administração da ractopamina nas dietas, elegendo-se artigos que utilizaram suínos em fase de terminação com suplementação de ractopamina durante 28 dias.

A base de dados utilizada foi composta por 18 publicações (Watkins et al., 1990; Stites et al., 1991; Bark et al., 1992; Dushea et al., 1993; Smith et al., 1995; Crome et al., 1996; Herr et al., 2000; Trapp et al., 2002; Marchant-Forde et al., 2003; Stoller et al., 2003; Armstrong et al., 2004; Brumm et al., 2004; See et al., 2004; Carr et al., 2005a, b; Mimbs et al., 2005; Weber et al., 2006; Marinho et al., 2007), nas quais os pesquisadores avaliaram níveis de inclusão de $0,5,10 \mathrm{e} / \mathrm{ou}$ 20ppm ractopamina, totalizando 2.991 suínos avaliados.

A média de peso inicial dos animais foi de $74,67 \pm 10,92 \mathrm{~kg}$ e a do peso final, $107,56 \pm 9,75 \mathrm{~kg}$. O tempo médio de duração dos períodos experimentais foi de $28 \pm 0,32$ dias

Realizou-se uma metanálise dos dados coletados que envolveu as seguintes etapas: análise exploratória do conjunto de dados, verificação das pressuposições estatísticas exigidas e realização do teste de homogeneidade. A análise exploratória do conjunto de dados foi realizada por meio do dispositivo gráfico box-plot $\mathrm{e}$ também pela verificação de "outliers" que visaram detectar a existência de observações discrepantes. A pressuposição de normalidade dos dados foi testada pelo teste Shapiro-Wilk, cuja hipótese de nulidade expressa que os dados apresentam distribuição normal. O teste Hartley foi empregado para a verificação da homogeneidade das variâncias. 
Atendidas as pressuposições, realizaram-se as análises de variância e de regressão para a obtenção das equações das variáveis avaliadas: consumo de ração (Cons), peso de carcaça (PCarc), rendimento de carcaça (\% Rend) e percentual de carne magra na carcaça $(\%$ CarnM), que resultaram nas seguintes equações:

Cons $=2,8964-0,022 \mathrm{x}+0,0008 \mathrm{x}^{2}, \mathrm{R}^{2}=0,97$;

PCarc $=79,265+0,4988 \mathrm{x}-0,0185 \mathrm{x}^{2}, \mathrm{R}^{2}=0,91$;

$\%$ Rend $=74,143+0,1056 \mathrm{x}, \mathrm{R}^{2}=0,97 \mathrm{e}$

$\%$ CarnM $=53,746+0,0854 x, R^{2}=0,98$.

Como cada equação está vinculada ao nível de ractopamina, foi possível formular as equações econômicas em função da variação do nível de ractopamina. A partir dessas informações, realizou-se uma simulação determinística do desempenho técnico-econômico de suínos terminados sob o efeito de ractopamina na dieta, por um período de 28 dias, com o auxílio de planilhas eletrônicas e programação computacional. A simulação caracterizou-se por ser determinística, uma vez que se utilizaram valores pontuais para determinar os resultados. Como a simulação está vinculada às equações de regressão que determinam o desempenho técnico dos animais, o desempenho econômico pode ser medido tanto pontualmente como por séries históricas de preços. Com isso, as equações econômicas foram escritas para aferição do custo da dieta mais custo de aquisição dos animais, da receita em sistema de remuneração pela venda dos animais vivos (sem bonificação), em sistema de remuneração por bonificação $(\mathrm{BF})$, e da análise do lucro obtido em cada modelo.

As equações de custo da dieta foram:

Custo da dieta $(\mathrm{R} \$$ Dieta $)=(\mathrm{Cons}) *(\mathrm{R} \$ / \mathrm{kg}) *($ Período $)$, em que:

Cons $=$ consumo e $\mathrm{R} \$ / \mathrm{kg}=$ custo unitário da dieta, excluído custo da ractopamina.

Custo do nível de ractopamina (R\$ Ract):

Custo unitário da ractopamina $(\mathrm{R} \$$ unit $)=$

(R\$/ppm*Cons)/100, em que:

$\mathrm{R} \$ / \mathrm{ppm}=$ custo de $1 \mathrm{ppm}$ de ractopamina; Cons= consumo da dieta e $100=$ batida padrão de $100 \mathrm{~kg}$ de dieta.

$\mathrm{R} \$$ Ract $=(\mathrm{NRD}) *(\mathrm{R} \$$ unit $) *($ período $)$, em que: $\mathrm{NRD}=$ nível de ractopamina na dieta; $\mathrm{R} \$$ unit= custo de $1 \mathrm{ppm}$ de ractopamina na dieta, e período $=$ período de consumo (28 dias).

Custo total da dieta $=(\mathrm{R} \$$ Ract $)+(\mathrm{R} \$$ Dieta $) ;$

Custo de aquisição dos animais $=(\mathrm{kg} \text { de } \mathrm{PV})^{*}(\mathrm{R} \$ / \mathrm{PV})$; Custo total $=$ custo total da dieta + custo de aquisição dos animais.
O custo da ractopamina foi determinado em consulta comercial com valor de R $\$ 0,008 / \mathrm{ppm}$, o custo da ração de terminação foi cotado em $\mathrm{R} \$$ $0,467 / \mathrm{kg}$ e o custo de aquisição dos animais em $\mathrm{R} \$ 2,5 / \mathrm{kg}$ de peso vivo. Esses valores podem ser atualizados em qualquer momento, permitindo a atualização dos resultados.

A equação de receita pelo sistema de bonificação (BF) proposto por Guidoni (2000) foi:

\section{Receita $\mathrm{BF}=$}

$\mathrm{R} \$ / \mathrm{PV} *((\mathrm{PCarc} / \%$ Rend $) *(23,6+(0,286 * \mathrm{PCarc})+\%$

CarnM), em que:

$\mathrm{R} \$ \mathrm{PV}=$ preço pago ao produtor por quilo de suíno vivo; $P C a r c=$ peso de carcaça; \%Rend= percentual de rendimento de carcaça e \%CarnM= percentual de carne magra da carcaça.

A equação seguinte foi desenvolvida para os cálculos dos resultados dos sistemas de remuneração por peso vivo (PV) dos animais.

Receita $\mathrm{PV}=$ peso vivo estimado $(\mathrm{kg}) * \mathrm{R} \$ / \mathrm{PV}$, em que:

$\mathrm{R} \$ \mathrm{PV}=$ preço pago ao produtor por quilo de suíno vivo e peso vivo estimado= (PCarc/\%Rend)*100.

Uma vez obtidas as equações, a receita e o custo total, a diferença entre elas resultou no lucro bruto de cada sistema. Para o teste da simulação, estipulou-se um limite máximo de 20ppm de ractopamina na dieta, que oscilou desde zero até $20 \mathrm{ppm}$, com variação de inclusão de $1 \mathrm{ppm}$. Com isso, a cada rodada da simulação, os valores econômicos foram gerados para futura análise.

Determinado o cenário padrão, foram realizados testes de sensibilidade econômica, oscilando os valores pagos pela ractopamina e os valores recebidos pelos animais vendidos. Para tal, foram testados três cenários para cada tipo de sistema de receita: um cenário pessimista, um cenário mais provável (cenário padrão) e um cenário otimista, tanto para o raciocínio de oscilação na receita como no custo, independentemente.

$\mathrm{Na}$ oscilação de receita, o cenário pessimista utilizou o valor de $\mathrm{R} \$ 2,19 / \mathrm{kg} \mathrm{PV}$, o cenário mais provável, R\$2,40/kg PV, e o cenário otimista, $\mathrm{R} \$ 2,60 / \mathrm{kg}$ PV.

Quanto à oscilação no custo, o cenário pessimista utilizou o preço comercial para a ractopamina 


\section{Brumatti e Kiefer}

acrescido de 15\%, o cenário mais provável utilizou o valor comercial normal, e o cenário otimista, o valor comercial da ractopamina descontado em 15\%. Os dados testados para receita foram obtidos mediante análise estatística dos valores pagos aos produtores por quilograma de peso vivo apresentados no Anualpec... (2007).

As análises estatísticas dos dados foram realizadas por intermédio do programa estatístico SAS/2001, a 5\% de significância.

\section{RESULTADOS E DISCUSSÃO}

Os resultados referentes ao desempenho técnico em relação ao peso de carcaça e consumo de ração são apresentados na Fig. 1. Evidencia-se que o ponto máximo para peso de carcaça no sistema de receita por bonificação foi atingido com $12 \mathrm{ppm}$ de ractopamina na dieta, e o ponto máximo para o sistema de receita para peso vivo com 10ppm. Quanto ao consumo de ração, independentemente do sistema de receitas, o ponto ótimo, no caso mínimo, foi de $14 \mathrm{ppm}$ de ractopamina.

À medida que se aumentou o nível de inclusão de ractopamina na dieta, o peso de carcaça observado no sistema de bonificação apresentou melhores resultados comparado aos obtidos no sistema de receita por peso vivo do animal. Tal fato pode ser explicado pela maior influência da ractopamina sobre as características quantitativas da carcaça, principalmente sobre o percentual de carne magra, em relação às variáveis de desempenho, sendo que estas são diretamente utilizadas na equação de bonificação da carcaça.

Estes resultados assemelham-se aos observados por Brumm et al. (2004), que constataram que a resposta à suplementação às dietas de suínos com ractopamina é dose dependente. Segundo Crome et al. (1996), embora promovam melhora do ganho e da eficiência alimentar, as doses mais elevadas de ractopamina (20ppm) promovem impacto mais pronunciado sobre as características quantitativas da carcaça. Além disso, o ganho de peso é otimizado com níveis mais baixos e diminuído com níveis próximos a 20ppm, em razão do efeito depressor da ractopamina sobre o consumo de ração.

Nas Fig. 2, 3, 4 e 5, apresentam-se os resultados obtidos na avaliação econômica da inclusão de ractopamina nas dietas de suínos em terminação. Estão agrupados em termos de custos e lucratividade para evidenciar a eficiência em custos mínimos e lucros máximos em cada cenário testado.

Na Fig. 2, mostram-se os valores obtidos para o cenário padrão em termos de custos e lucros. $\mathrm{O}$ ponto ótimo em termos de custo mínimo é o mesmo para o sistema de receita por bonificação e por peso vivo, e ambos apresentaram como custo mínimo 5ppm de ractopamina na dieta. Quanto à variação no custo, o valor foi igual a $\mathrm{R} \$ 2,46 /$ cabeça, quando se compararam os extremos.

O lucro máximo ocorreu no sistema de receita por bonificação com a adição de ractopamina em relação ao sistema de receita por peso vivo. O lucro máximo no sistema por bonificação foi obtido com a inclusão de 12 ppm de ractopamina, enquanto o lucro máximo obtido pelo sistema de receita por peso vivo atingiu seu ápice em 10ppm de ractopamina.

Quanto ao lucro para o sistema de receita por bonificação, observa-se que o valor inicial, ou seja, aquele que não contém adição de ractopamina, apresenta o menor valor de lucro, R\$43,01/cabeça, e quando comparado com o valor ótimo gera diferencial de até $\mathrm{R} \$ 11,15 /$ cabeça. Contudo, ao analisar os lucros obtidos pelo sistema de receita por peso vivo, observa-se que necessariamente o menor valor atingido corresponde à inclusão de $20 \mathrm{ppm}$ de ractopamina, apresentando valor igual a $\mathrm{R} \$ 41,74 /$ cabeça, menor do que o valor inicial estimado em R $\$ 42,97 /$ cabeça; ao comparar com o valor ótimo, gera diferencial de até $\mathrm{R} \$ 7,60 /$ cabeça.

$\mathrm{Na}$ Fig. 3, apresenta-se o comportamento da diferença no lucro obtido quando os sistemas de receita são comparados. Observa-se que o diferencial, em termos de lucro, para o sistema de receita bonificado, é crescente e positivo em relação àquele do sistema de receita por peso vivo. Tal comportamento é coerente com outros da literatura, uma vez que diversos pesquisadores (Schinckel et al., 2002; Apple et al., 2004; See et al., 2004; Perez et al., 2006) evidenciaram os efeitos positivos da ractopamina sobre as características quantitativas da carcaça. 


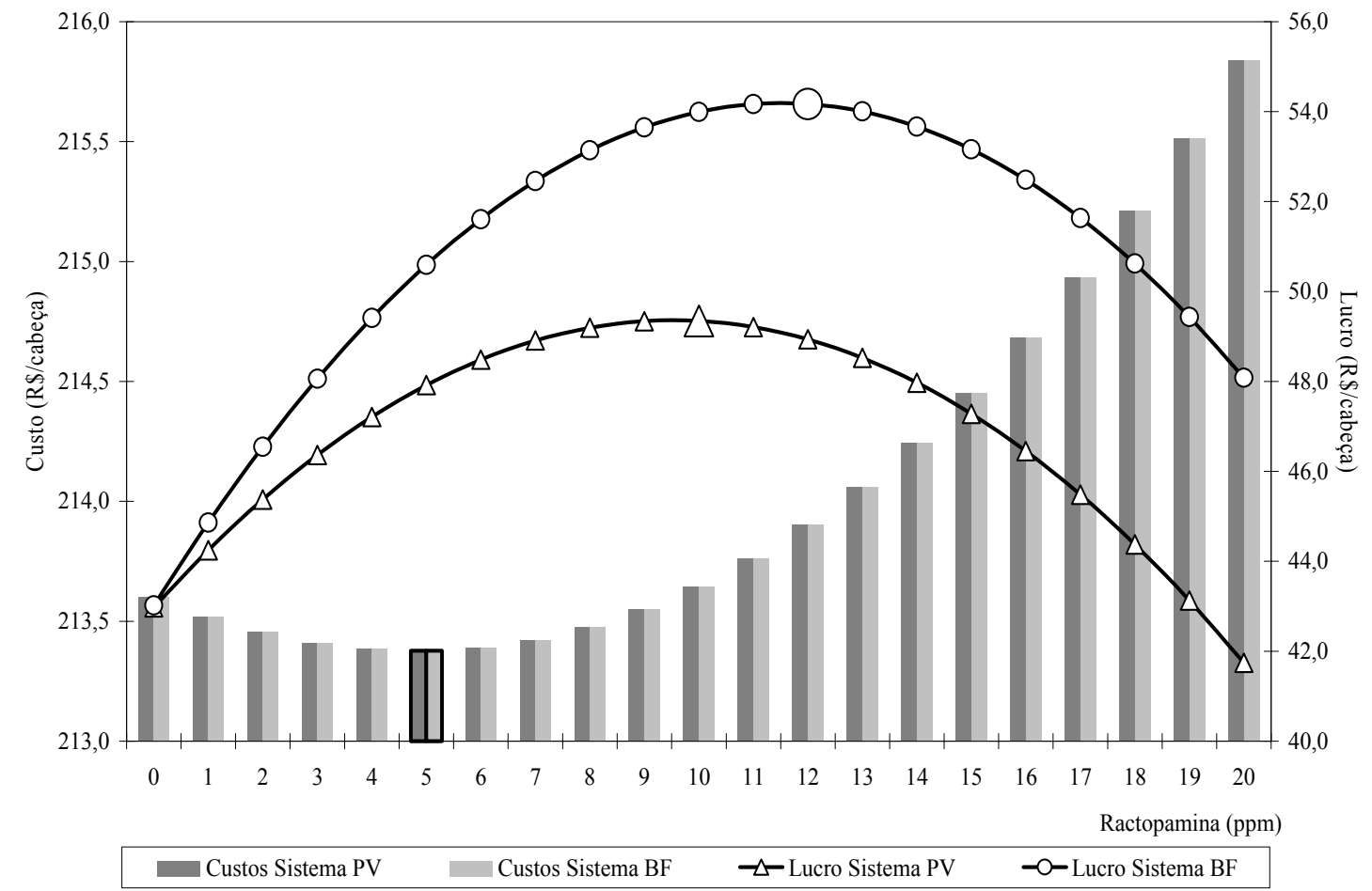

Figura 1. Resultados obtidos para peso de carcaça e consumo de ração em função da inclusão de ractopamina na dieta.

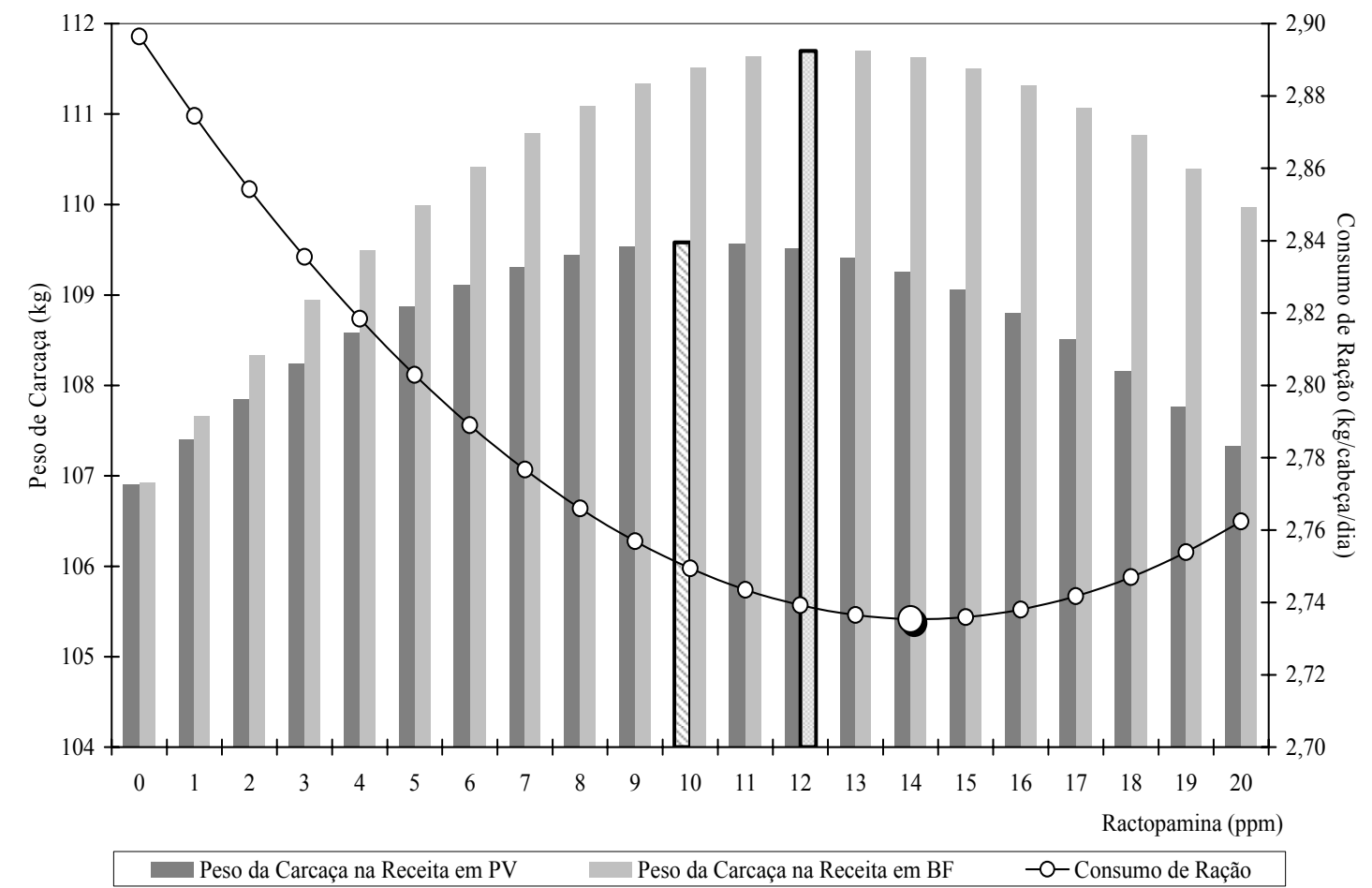

Figura 2. Resultados obtidos para custos e lucros no cenário padrão em função da inclusão de ractopamina na dieta para cada sistema de receita testado. 


\section{Brumatti e Kiefer}

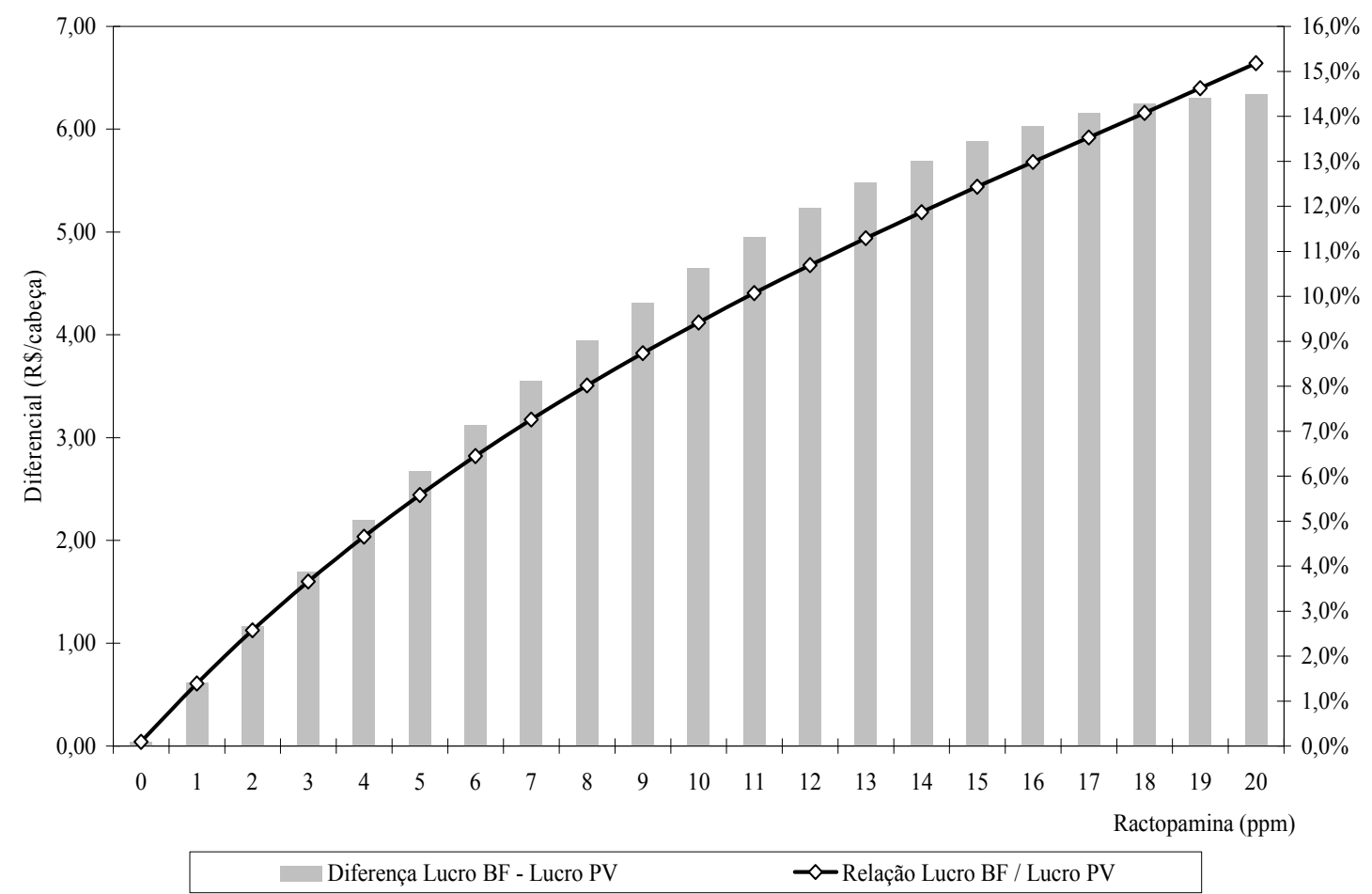

Figura 3. Relação dos lucros obtidos em cada sistema de receita em função da inclusão de ractopamina na dieta.

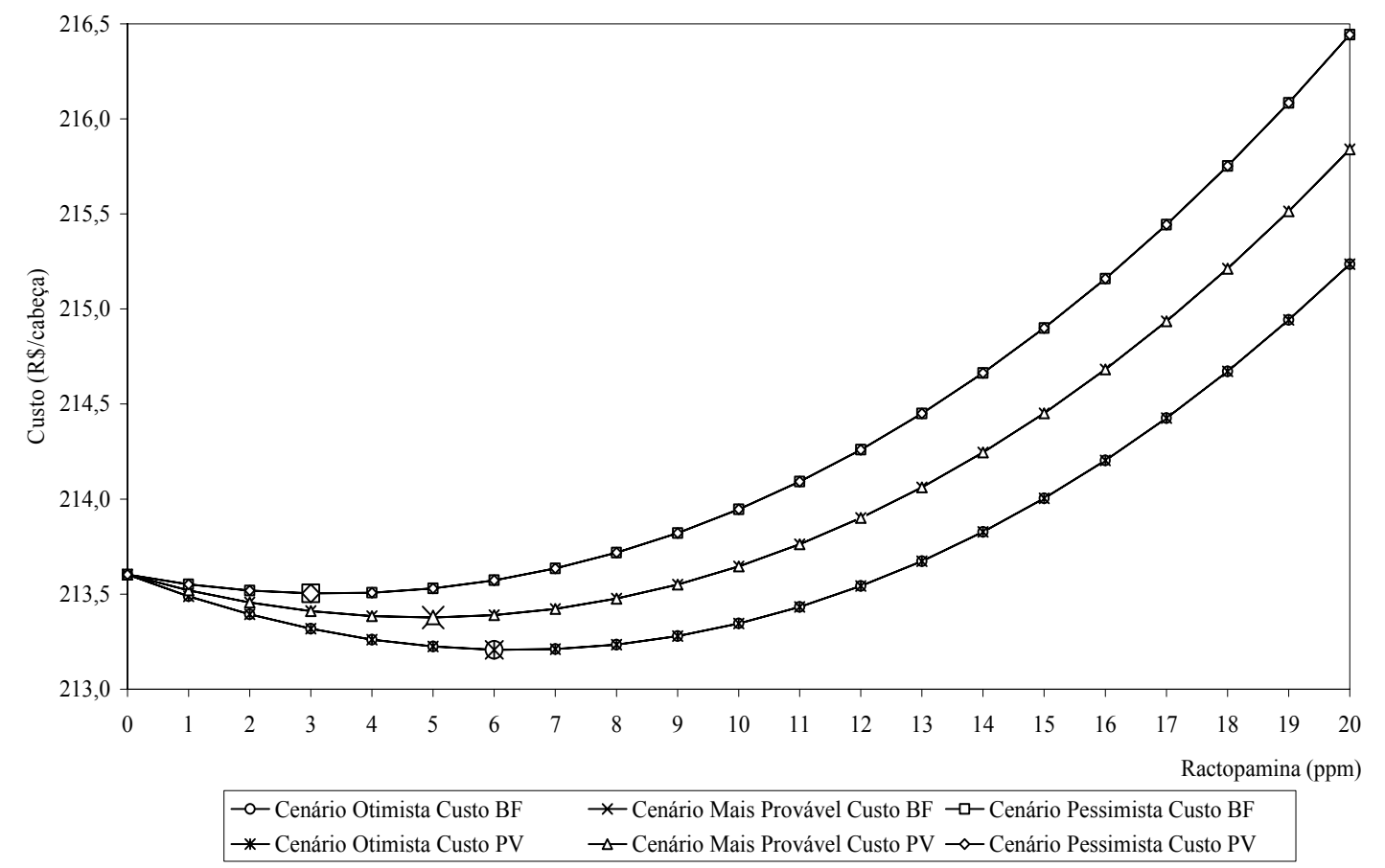

Figura 4. Resultados de custos obtidos nos cenários otimista, mais provável e pessimista em função da inclusão de ractopamina na dieta. 


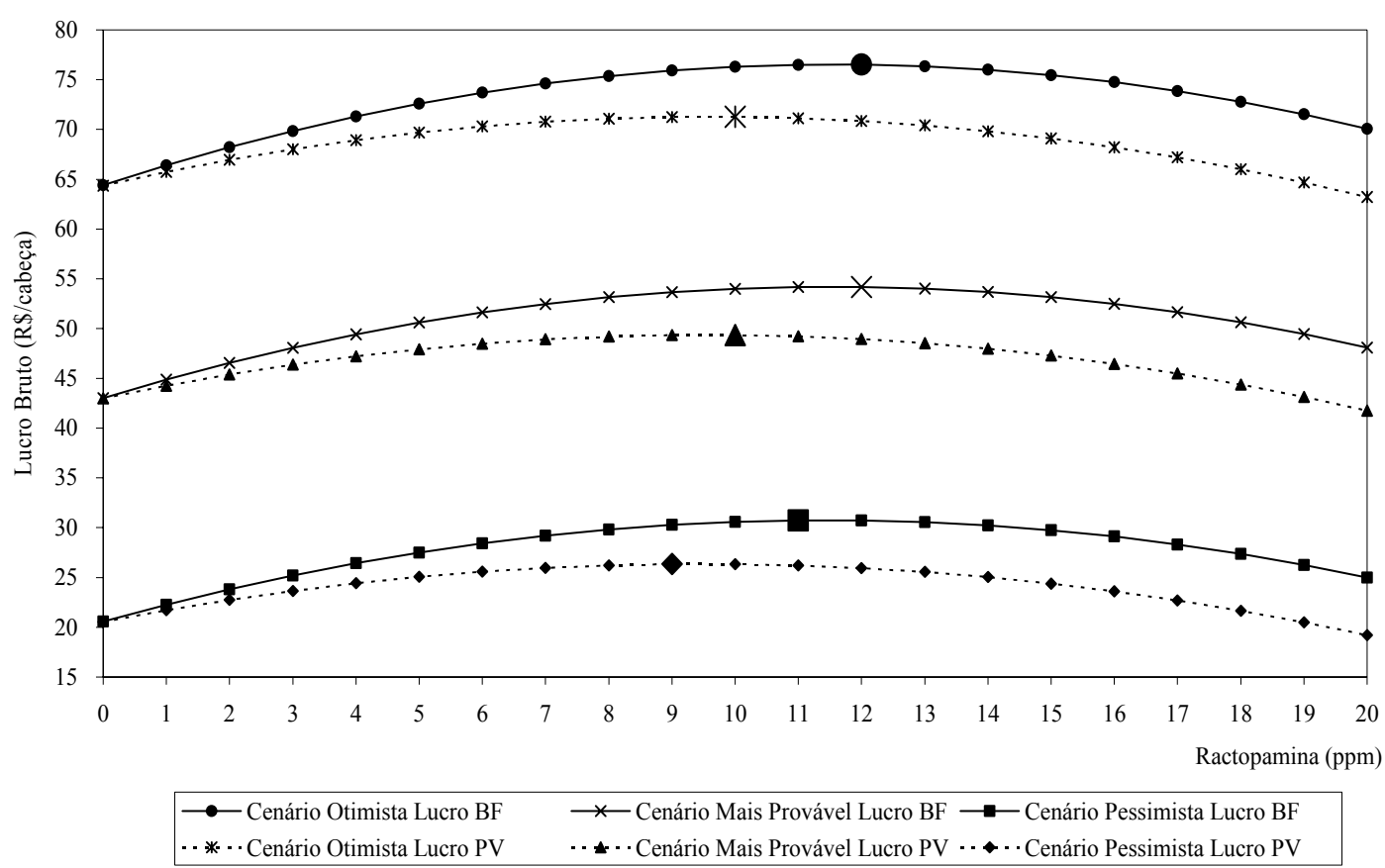

Figura 5. Resultados de lucros obtidos nos cenários otimista, mais provável e pessimista em função da inclusão de ractopamina na dieta.

Nas Fig. 4 e 5, apresentam-se os resultados obtidos nas análises de sensibilidade quando se oscilam os valores para a receita e para o custo. Como o sistema de receita não influencia a equação de custo proposta, os resultados obtidos foram iguais, independentemente dos sistemas de receita avaliados.

Entre os cenários propostos, o aumento no custo da ractopamina modificou o comportamento da curva e gerou, com isso, novo ponto ótimo, em termos de custo mínimo, em que, no cenário pessimista, o novo nível foi de $3 \mathrm{ppm}$ de ractopamina. No cenário otimista, que simulou a redução no custo da ractopamina, houve deslocamento favorável da curva, que resultou em custo mínimo em $6 \mathrm{ppm}$ de ractopamina. No entanto, vale a ressalva de que a amplitude da variação é pequena, tanto em termos monetários como em termos quantitativos de uso da ractopamina.

Quanto aos resultados de lucro em razão da oscilação nas receitas, observou-se maior amplitude em relação aos resultados de oscilação nos custos. Tal amplitude, comparada às médias obtidas, chega à diferença de até $\mathrm{R} \$ 49,00 /$ cabeça, se se levar em conta o cenário mais positivo com o mais negativo. Observa-se também que a curva de lucratividade apresenta o mesmo comportamento da curva de produção, inclusive com os melhores resultados para os cenários com receita por sistema de bonificação.

Todavia, o cenário pessimista, aquele que considerou os piores valores de receita, apresentou decréscimo no nível ótimo de inclusão de ractopamina, atingindo valores de 11 e 9ppm, respectivamente, para os sistemas de receita por bonificação e sistema por peso vivo.

O comportamento dos resultados para o sistema de receita por peso vivo manteve-se igual, considerando que os piores resultados aparecem com a maior inclusão da ractopamina na dieta. Estes resultados, que evidenciam melhor desempenho econômico no sistema de receita por bonificação, assemelham-se aos obtidos por Cantarelli (2007), que avaliaram o impacto da suplementação de $5 \mathrm{ppm}$ de ractopamina associado ou não à restrição alimentar em rações com elevado teor de lisina total sobre as características de carcaça e viabilidade econômica, e concluíram que a utilização da ractopamina melhora as características de carcaça 


\section{Brumatti e Kiefer}

e viabiliza economicamente seu uso. O mesmo se observou no trabalho de $\mathrm{Li}$ et al. (2003), que realizaram análise de sensibilidade para testar níveis de suplementação de ractopamina na dieta de suínos, ao concluírem que, dependendo do esquema de pagamento realizado ao produtor e da fase de vida, ocorrerá impacto significativo sobre a eficiência no uso da ractopamina.

\section{CONCLUSÕES}

A tomada de decisão por parte do produtor em relação ao nível de suplementação de ractopamina na dieta dos suínos em terminação dependerá do tipo de comercialização empregada no sistema de produção. A recomendação técnica da indústria nem sempre condiz com a eficiência econômica no sistema produtivo, necessitando ajustes pelos produtores quanto ao nível de ractopamina ideal.

\section{REFERÊNCIAS BIBLIOGRÁFICAS}

ANUALPEC: Anuário da Pecuária Brasileira. São Paulo, SP: IFNP, 2007.

APPLE, J.K.; MAXWELL, C.V.; BROWN, D.C. et al. Effects of dietary lysine and energy density on performance and carcass characteristics of finishing pigs fed ractopamine. J. Anim. Sci., v.82, p.3277-3287, 2004.

ARMSTRONG, T.A.; IVERS, D.J.; WAGNER, J.R. et al. The effect of dietary ractopamine concentration and duration of feeding on growth performance, carcass characteristics, and meat quality of finishing pigs. J. Anim. Sci., v.82, p.3245-3253, 2004.

BARK, L.J.; STAHLY, T.S; CROMWELL, G.L. et al. Influence of genetic capacity for lean tissue growth on rate and efficiency of tissue accretion in pigs fed ractopamine. J. Anim. Sci., v.70, p.3391-3400, 1992.

BRUMM, M.C.; MILLER, P.S.; THALER, R.C. Response of barrows to space allocation and ractopamine. J. Anim. Sci., v.82, p.3373-3379, 2004.

CANTARELLI, V.S. Ractopamina em rações para suínos em terminação com alimentação à vontade ou restrita. 2007. 108f. Tese (Doutorado em Zootecnia) - Universidade Federal de Lavras, Lavras, MG.
CARR, S.N.; IVRES, D.J.; ANDERSON, D.B. et al. The effects of ractopamine hydrochloride on lean carcass yields and pork quality characteristics. J. Anim. Sci., v.83, p.2886-2893, 2005a.

CARR, S.N.; RINCKER, P.J.; KILLEFER, J. et al. Effects of different cereal grains and ractopamine hydrochloride on performance, carcass characteristics, and fat quality in latefinishing pigs. J. Anim. Sci., v.83, p.223-230, 2005 b.

CROME, P.K.; McKEITH, F.K.; CARR, T.R. et al. Effect of ractopamine on growth performance, carcass composition, and cutting yields of pigs slaughtered at 107 and 125 kilograms. J. Anim. Sci., v.74, p.709-716, 1996.

DUNSHEA, F.R.; KING, R.H.; CAMPBELL, R.G. et al. Interrelationships between sex and ractopamine on protein and lipid deposition in rapidly growing pigs. J. Anim. Sci., v.71, p.29192930, 1993.

GUIDONI, A.L. Melhoria de processos para tipificação e valorização de carcaças suínas no Brasil. CONFERÊNCIA INTERNACIONAL VIRTUAL SOBRE QUALIDADE DE CARNE SUÍNA, 1, 2000. Disponível em: $<$ http://www.cnpsa.embrapa.br/sgc/sgc_publicac oes/anais00cv_guidoni_pt.pdf $>$. Acessado em: 15 mar. 2008.

HERR, C.T.; YAKE, W.; ROBSON, C. et al. Effect of nutritional level while feeding paylean to late-finishing swine. Purdue Univ. Swine Day, v.21, p.89-95, 2000.

LI, N.; PRECKEL, K.A.F.; SCHINCKEL, A.P. Analysis of economically optimal nutrition and marketing strategies for Paylean ${ }^{\circledR}$ usage in hog production. J. Agric. Res. Econ., v.28, p. 272286, 2003.

MARCHANT-FORDE, J.N.; LAY Jr., D.C.; PAJOR, E.A. et al. The effects of ractopamine on the behavior and physiology of finishing pigs. $J$. Anim. Sci., v.81, p.416-422, 2003.

MARINHO, P.C.; FONTES, D.O.; SILVA, F.C.O. et al. Efeito da ractopamina e de métodos de formulação de dietas sobre o desempenho e as características de carcaça de suínos machos castrados em terminação. Rev. Bras. Zootec., v.36, p.1061-1068, 2007. 
MIMBS, K.J.; PRINGLE, T.D.; AZAIN, M.J. et al. Effects of ractopamine on performance and composition of pigs phenotypically sorted into fat and lean groups. J. Anim. Sci., v.83, p.1361-1369, 2005.

PÉREZ, A.; OBISPO, N.E.; PALMA, J.P. et al. Efectos de la ractopamina y lisina sobre la deposición de grasa en cerdos seleccionados magros en la fase de engorde. Zootec. Trop., v.24, p.435-455, 2006.

ROPPA, L. Perspectivas da produção Mundial de Carnes, 2006 a 2030. In: CONGRESSO LATINO AMERICANO DE SUINOCULTURA, 3., 2006, Foz do Iguaçu. Anais... Foz do Iguaçu: [s.n.], 2006. CD-ROOM.

SCHINCKEL, A.P.; RICHERT, B.T.; HERR, C.T. Variation in the response of multiple genetic populations of pigs to ractopamine. J. Anim. Sci., v.80, suppl. E2, p.E85-E89, 2002.

SEE, M.T.; ARMSTRONG, T.A.; WELDON, W.C. Effect of a ractopamine feeding program on growth performance and carcass composition in finishing pigs. J. Anim. Sci., v.82, p.2474-2480, 2004.

SMITH, W.C.; PURCHAS, R.W.; VAN ENKEVORT, A. et al. Effects of ractopamine on the growth and carcass quality of entire male and female pigs fed ad libitum or at a restricted level. N.Z. J. Agric. Res., v.38, p.373-380, 1995.
STITES, C.R.; McKEITH, F.K.; SINGH, S.D. et al. The effect of Ractopamina hydrochloride on the carcass cutting yields of finishing swine. $J$. Anim. Sci., v.69, p.3094-3101, 1991.

STOLLER, G.M.; ZERBY, H.N.; MOELLER, S.J. et al. The effect of feeding ractopamine (paylean) on muscle quality and sensory characteristics in three diverse genetic lines of swine. J. Anim. Sci., v.81, p.1508-1516, 2003.

TRAPP, S.A.; RICE, J.P.; KELLY, D.T. et al. Evaluation of four ractopamine use programs on pig growth an carcass characteristics. Purdue University - Swine Research Report, p.62-71, 2002.

WATKINS, L.E.; JONES, D.J.; MOWREY, D.H. et al. The effect of various levels of ractopamine hydrochloride $\mathrm{o}$ the performance and carcass characteristics of finishing swine. $J$. Anim. Sci., v.68, p.3588-3595, 1990.

WEBER, T.E.; RICHERT, B.T.; BELURY, M.A. et al. Evaluation of the effects of dietary fat, conjugated linoleic acid and ractopamine on growth performance, pork quality and fatty acid profiles in genetically lean gilts. J. Anim. Sci., v.84, p.720-732, 2006. 